\title{
Cultura e psicopatologia: um ponto de vista fenomenológico*
}

\author{
Arthur Tatossian
}

O encontro ou a oposição entre psiquiatria e cultura não é recente, mesmo sem que se remonte aos escritos dos grandes viajantes do século XVIII, e aos seus espantos, a psiquiatria encontrou a cultura com a viagem de Kraepelin a Java no início do século XX e seus esforços para aí encontrar as categorias psiquiátricas em voga nas antigas edições do Tratado.

\section{Abordagens do problema: cultura e psicopatologia}

A abordagem do problema é dupla: prática e teórica.

Abordagem prática

Observa-se atualmente a multiplicação de situações psiquiátricas interculturais.

O psiquiatra ocidental, tratando um doente não-ocidental, se encontra em uma situação que coloca um problema cotidiano no Ocidente; este problema apareceu pelo fato da expansão da psiquiatria

* Conferência proferida em 20 de fevereiro de 1992 na Sociedade de Psiquiatria de Nice. Publicada em Tatossian, A. Psiquiatrie phénomenologique. Paris: Etim, 1997. Texto traduzido por Virginia Moreira (Universidade de Fortaleza) e José Celio Freire (Universidade Federal do Ceará). Revisão técnica realizada por Virginia Moreira. 
ocidental, testemunhado pela experiência de Colombo em Dakar. Tampouco devese esquecer o caso inverso, aquele do doente ocidental tratado fora de seu país de origem, ilustrado pelo problema de colaboradores cooperadores.

O problema existe, e é mais difícil de resolver, na medida em que a perturbação mental é menos profunda. Para Devereux, a psicose tem um efeito de “desculturação" muito maior que a neurose ou a psicopatia. O psiquiatra é, então, relativamente menos incomodado pelo filtro cultural diante dos psicóticos. De fato, a compreensão do doente implica uma "neutralidade cultural" por analogia com a "neutralidade afetiva” do analista; esta "neutralização” é de alguma forma automática se psiquiatra e doente compartilham a mesma cultura.

Existem problemas similares, apesar de tudo, no interior de uma mesma cultura à medida que as sociedades complexas comportam subculturas mais ou menos estrangeiras entre elas, bojo das psiquiatrias subculturais específicas da criança, do adolescente, do velho e também da "psiquiatria dos pobres”, quer dizer, das classes sociais desfavorecidas; a psiquiatria setorizada é em parte uma "psiquiatria dos pobres".

\section{Abordagem teórica}

A psiquiatria transcultural clássica parte da idéia de que as categorias psiquiátricas ocidentais são universais, mas que a cultura modifica os conteúdos por ação "pathoplástica"1. O problema é simplesmente de determinar as formas sintomáticas tomadas pelas afecções psiquiátricas nas sociedades extra-ocidentais, mas a assimilação dos distúrbios psíquicos nas sociedades foi penosa e alguns propõem um tratamento através de uma dieta restrita.

A psiquiatria transcultural recente, por exemplo, com Klemman (1997), ameaça muito mais a validade da psiquiatria ocidental. Com efeito, a medicina somática pode referir-se ao invariante universal que é o corpo anátomo-fisiológico quanto mais o psiquismo é penetrado de cultura e não fornece este tipo de invariante. Para este autor, a psiquiatria nas várias sociedades é tão variável quanto as regras de puericultura, as boas maneiras à mesa ou os códigos jurídicos.

A psiquiatria é uma maneira para a sociedade ocidental regulamentar o problema de seus "desvios", mas existem outras maneiras de fazê-lo e logo cada cultura tem uma psiquiatria própria: a ocidental não é privilegiada. É mesmo necessário sublinhar que as culturas podem regulamentar os problemas sem constituir uma psiquiatria ou um equivalente, porque as noções de doenças mentais, de etiologia e

1. A palavra "patoplástica” inexiste em português. Em francês: pathoplastique. O sentido é de uma ação exterior (da cultura, no caso) que modificaria a doença ou seu sentido. (N. da T.) 
de tratamento não são universais. Um exemplo clássico é o de Tabanka em Trindade (Little-Wood, 1985). O homem abandonado por sua esposa dorme mal, não tem apetite, se sente desesperado e desvalorizado, é agressivo e, às vezes, tenta se matar. Para nós trata-se de uma “depressão reativa”, mas em Trindade o Tabanka não é uma doença e sim uma manifestação culturalmente admitida, não concernindo aos profissionais de saúde. Dito de outra maneira, com esta nova psiquiatria transcultural, a noção mesma de doença ou perturbação mental se torna um fato cultural próprio da sociedade de tipo ocidental e não é generalizável.

\section{Efeitos da cultura em psiquiatria}

A cultura pode influir sobre os quadros clínicos e sobre a validade das teorias, mas também sobre a definição do normal e do patológico.

Variabilidade clínica

Variações de freqüência dos quadros clínicos

A pesquisa OMS (estudo-piloto internacional da esquizofrenia, Sartorius e colaboradores, 1986) mostrou que a esquizofrenia nuclear tem uma taxa mais ou menos estável no mundo inteiro, mas as síndromes esquizofrênicas do "espectro da esquizofrenia” variam muito em freqüência, de três vezes entre a Índia e a Dinamarca, o que é, sem dúvida, generalizável.

Por outro lado, existem as síndromes ditas "ligadas à cultura”, quer dizer, supostamente ligadas a uma só cultura.

Nas sociedades não-ocidentais, o Amok (furores assassinos) na Malásia, a psicose Windigo da América do Norte, a histeria ártica dos Esquimós (ataques zoomórficos) constituem exemplos, mas se observa uma rarefação progressiva destas síndromes, ou sua "inexistência”. Assim, a psicose Windigo parece mais um mito do que um estado psicológico real.

No Ocidente, a anorexia mental ou os distúrbios bulímicos parecem assimilados à cultura e ao excesso alimentar.

Variações semiológicas

A melancolia é dominada pela culpabilidade no Ocidente, enquanto o é principalmente pela vergonha no Japão ou na Ásia. Para Kimura, esta variação não impede a transcendência à cultura das psicoses ditas endógenas. $\mathrm{O}$ japonês, em particular, vive de fato muito próximo à natureza e por isto muito perto dos outros, particularmente da família: ele nunca está de fato só, contrariamente ao Ocidental, adepto 
do individualismo, donde a diferença: dificilmente é possível experimentar vergonha em relação a si mesmo, mas sim a culpa. O vivido é de fato o mesmo no japonês ou no ocidental, mas se exprime como vergonha perante outrem, o outro para um, e como culpa diante de si mesmo para o outro.

A depressão, em um plano mais geral, é interessante de estudar. Admite-se de bom grado que o vivido depressivo é de ordem psíquica na sociedade ocidental e de ordem somática nas sociedades não-ocidentais. De fato, mesmo na sociedade ocidental, a depressão é uma vivência corporal em um certo número de sujeitos, e o é de maneira totalmente habitual em alguns. Por exemplo, na criança, ou nas pessoas de nível sociocultural baixo, esta somatização é mesmo suficientemente freqüente para que se tenha individualizado a "depressão mascarada”, o que evoca que a "verdadeira” depressão é psíquica. De fato, o paciente "escolhe” a manifestação somática ou a manifestação psíquica de acordo com seus recursos [suas fontes] e seus objetivos.

Leff (1973) mostrou que a diferenciação de vocabulário afetivo é muito pobre em muitas das línguas que distinguem mal a depressão da ansiedade ou mesmo da tensão colérica, ao contrário de nossas línguas ocidentais, ainda que estas também as diferenciavam mal inicialmente. Por exemplo, no inglês antigo, as palavras designando o medo ansioso, a cólera e a tristeza têm uma mesma raiz angh, evocando uma vivência corporal.

Kirmayer estudou a "geografia da somatização" e mostrou que ela diz menos da cultura que a ausência relativa de disponibilidade de tratamentos psicológicos.

Anget (1973) concluiu que a psicologização da depressão é a eventualidade atípica e não a somatização: a depressão psíquica é um aspecto bastante específico da civilização cristã ocidental e mesmo da minoria ocidental das cidades com recursos psicológicos desenvolvidos. No fundo, o que nos ensinam estes exemplos é que não é a vivência depressiva que varia - e que fundamentalmente é mais corporal que psíquica -, mas a formulação desta vivência ao nível sintoma e não ao nível do fenômeno, quer dizer, do vivido propriamente dito.

\section{A variabilidade evolutiva}

Admite-se perfeitamente que as esquizofrenias têm um melhor prognóstico nas sociedades ditas tradicionais que nas sociedades ocidentais. A explicação certamente não é de que se trata de formas esquizofrênicas, visto que a esquizofrenia nuclear parece de freqüência pouco diferente segundo as sociedades; a diferença, na verdade, parece diminuir ao menos nas grandes cidades não-ocidentais, por exemplo africanas, à medida que elas se ocidentalizam, felizmente ou infelizmente. Na medida em que ela existe, ainda, em todo caso, a diferença provém sobretudo do sentido muito diferente de doença mental que nas sociedades tradicionais é um fenômeno 
social mais que um fenômeno individual e dá lugar a um suporte social muito mais sólido e durável, ainda que não inatingível... mas se toca aí em um outro tipo de efeito da cultura de sustentação levando à teorização psiquiátrica.

Variabilidade cultural da teorização psiquiátrica

Teoria da atribuição

Esta teoria está talvez na base de toda teoria psiquiátrica. De fato, ela faz parte da vivência do doente que pode, ele mesmo, atribuir seu mal a uma causa externa a ele, ou a uma causa interna pela qual ele é, portanto, responsável. Wessmann e colaboradores (1975) mostraram que o deprimido melhora muito mais rápido, mesmo sem terapia química, a igual intensidade depressiva, quando a atribuição externa predomina. Ora, as sociedades tradicionais favorecem muito a atribuição externa fazendo da doença um mal social, o que "desresponsabiliza” o sujeito doente, ao contrário das sociedades ocidentais individualizantes.

O preço a pagar é, sem dúvida, que em caso de doença somática a responsabilidade pode ser jogada sobre o corpo, o qual pode ser considerado como diferente de si, enquanto isto não é mais possível para a doença psíquica. Ainda se faz necessário reconhecer que, atualmente, mesmo a doença somática tende a ser atribuída à responsabilidade do sujeito nas sociedades ocidentais que impõem medidas preventivas mais e mais numerosas: não se deve fumar, deve-se fazer esporte, é necessário passar nos exames físicos de checagem etc.

Teorias psiquiátricas propriamente ditas

Na medida em que elas pretendem trazer uma explicação dos distúrbios das perturbações mentais, as teorias psiquiátricas são um desenvolvimento desta atribuição externa ou interna.

Se as teorias biológicas ou sociais, incluindo a antipsiquiatria, desenvolvem uma atribuição externa, as teorias psicodinâmicas desenvolveram, sobretudo, uma atribuição interna.

Em certa medida, a teoria psicanalítica favorece a atribuição interna, a partir do momento em que ela abandonou a idéia de traumatismo infantil real, no que ela é eminentemente ocidental, ainda que a atribuição seja feita ao inconsciente e não à consciência do sujeito.

O problema colocado pelas contribuições transculturais à psicanálise dirige-se ao valor universal desta, em particular sobre o papel crucial do Édipo.

Nos anos 1920, a evidência descoberta por Malinowski, em certas sociedades primitivas, de que não é o pai mas o irmão da mãe, nas sociedades matrilineares, 
quem é o representante da lei, parecia ter posto em perigo este valor universal do Édipo, tendo como conseqüência que a psicanálise podia ser compreendida como o estudo psicossociológico de uma certa classe burguesa de autóctones vienenses no fim do século XIX, pertencendo a uma sociedade patriarcal. De fato, a resposta - fácil - foi que o Édipo é ainda sempre válido nas sociedades de tipo matrilinear, mas que simplesmente o irmão materno toma o lugar do pai.

Devereux retomou o problema e mostrou, por exemplo, a propósito do aborto, que os tipos de comportamento cultural a respeito, no conjunto das sociedades, correspondem exatamente ao inventário exaustivo das pulsões, dos desejos e dos fantasmas ressaltados pela psicanálise na sociedade ocidental, sendo a única diferença que cada sociedade faz sua própria escolha do que recalca e do que permite a atualização cultural. Existe, portanto, de qualquer maneira, uma unidade psíquica da humanidade e, portanto, uma psicopatologia universal.

Problema das classificações psiquiátricas

A psiquiatria transcultural se interessou muito pelas classificações psiquiátricas populares da folk psychiatry que são muito diferentes da classificação ocidental, mesmo se as diferenças comuns ocidentais tiveram suas divergências até o bem feliz DSM-III. Por exemplo, se pode lembrar a ternura mais ou menos isolada dos franceses pela gula delirante e pela psicose alucinatória crônica. Mas existem duas maneiras de trabalhar sobre as classificações populares. A primeira é de considerar que são aproximações da classificação ocidental e, portanto, busca-se ligar as unidades individualizadas em uma sociedade não ocidental a tal ou tal unidade ocidental, freqüentemente com resultados lembrados muito divergentes. A segunda, que corresponde à tendência atual, consiste sobretudo em sublinhar a diferença não apenas do conteúdo das classificações mas também o de sua estrutura. Por um lado, estas classificações populares não visam tanto a descrição das perturbações, mas sim sua ligação a tal ou tal causa - e portanto a tal ou tal meio de fazê-los desaparecer - por outro lado, freqüentemente não são lembradas as classificações psiquiátricas, mas antes mais as classificações de situações culturais específicas, impondo certas reações sociais. Muito curiosamente, estas classificações populares são tão obscuras para nós quanto as classificações das doenças no Ocidente, antes da medicina moderna: um exemplo é fornecido pela melancolia na Idade Média, que é mais uma palavra-à-mão que uma categoria psiquiátrica. De qualquer maneira, antes de se chegar a classificar as manifestações psíquicas patológicas é necessário definir o que é patológico e, portanto, o que é normal. 


\section{Diferença normal/patológico e relativismo cultural}

Durante muito tempo a noção de relativismo cultural de normal e de patológico foi o argumento maior para se pedir uma psiquiatria para cada cultura e, por último, para contestar a validade em si da psiquiatria. Mostrou-se, então, aos psiquiatras ocidentais que os estados de transe são perfeitamente admitidos por algumas sociedades, que as alucinações são normais nos índios das Planícies, que a dissipação frenética de seus bens com uma intenção de prestígio social (o potlach) é institucionalizado em tal cultura e não tem nada a ver com a megalomania patológica ou ainda que, em alguns malásios, a suspeição sistemática do vizinho em caso de má colheita, ou do cônjuge quando um dos membros do casal morre, não tem nada a ver com patologia; em outras palavras, o mesmo comportamento pode ser patológico aqui e normal lá.

Por volta de 1860, Griesinger já respondia a este problema: “Dois indivíduos podem dizer ou fazer exatamente a mesma coisa, por exemplo, exprimir uma crença sobre a influência dos feiticeiros, ou a fé de estar condenado à eternidade. $\mathrm{O}$ observador que sabe o que isto quer dizer declarará um destes indivíduos alienado e, o outro, são de espírito; o que torna esta interpretação possível é a consideração de todas as circunstâncias concomitantes e de uma experiência pessoal aprofundada das diferentes formas de loucura".

Toda a questão é saber o que quer dizer "o mesmo comportamento". Se isso quer dizer estritamente os comportamentos materiais, diretamente observáveis, incluindo a significação objetiva dos gestos feitos e das palavras ditas, estes são efetivamente os mesmos comportamentos no malásio desconfiado e no delirante ocidental perseguido. É bem verdade que o mesmo comportamento é patológico aqui e normal lá. Se o mesmo comportamento inclui a vivência, quer dizer, a significação subjetiva dos gestos e das palavras, se o comportamento não é apenas o sintoma de uma vivência considerada como inacessível mas incluída na vivência, quer dizer, a significação, dito de outra forma, se o comportamento é considerado como fenômeno global, justamente, não é mais o mesmo comportamento.

A hipótese do relativismo cultural põe em perigo apenas a psiquiatria fundada sobre o sintoma, quer dizer, uma psiquiatria que, muito modestamente, estima não poder ir além do que é exteriormente observável, o que não é a psiquiatria real, já que a psiquiatria percebe o sentido do comportamento, quer dizer, o vivido, e porque o vivido integra o horizonte cultural daquele que ela observa. O malásio e o delirante têm comportamentos “análogos”, mas não “homólogos” (Wegroski).

É aí, na natureza mesma da experiência psiquiátrica autêntica, que se instaura a divergência entre sociologia e psiquiatria na definição do normal. Para o sociólogo, o comportamento se reduz aos meros dados materiais e ele não pode ser normal em si mesmo ou patológico em si mesmo, ver segundo critérios externos, por exem- 
plo, o grau de adaptação social ou a freqüência relativa na sociedade em jogo: é a definição do desvio, mas não da normalidade, e o desvio, por si mesmo, pode ser normal ou patológico.

Em compensação, um psiquiatra não considera um comportamento como patológico em razão da raridade de sua inadaptação à sociedade, mas pela sua significação, quer dizer, pelo vivido que o estrutura. O psiquiatra pode deixar de considerar as condutas sexuais minoritárias, em uma sociedade, como anormais e pode considerar como patológico um comportamento freqüente e bem adaptado, em uma sociedade, quando ele estima que o sujeito não é livre de adotar este comportamento.

A única definição aceitável de patológico é, sem dúvida, a de Blankenburg dizendo que um comportamento ou uma vivência são patológicos quando o-sujeito-não-pode-não-apresentar este comportamento, ou não-pode-não-experimentar esta vivência. É, por exemplo, desta "normalidade patológica” que fala Tellenbach a respeito do Typus melancholicus, no entanto, hiperadaptado socialmente.

Para a psiquiatria é bem uma "patologia da liberdade", e a liberdade, esta se percebe, não é inferida como a não-liberdade.

À guisa de conclusão, eu direi de bom grado que os quadros clínicos, a freqüência e a evolução das perturbações psiquiátricas são diferentes segundo a influência que as sociedades e a cultura têm sobre estes.

Se compete à psiquiatria limitar-se a ressaltar a presença ou ausência dos sintomas, é necessário, com certeza, uma psiquiatria para cada cultura; e na verdade esta psiquiatria poderia apenas ressaltar os comportamentos desviantes e não seria, talvez, uma psiquiatria propriamente dita, mas mais uma tarefa sociológica e um simples capítulo da sociologia desta cultura.

Em compensação, se compete à psiquiatria perceber o sentido do sintoma, o que compreende seus componentes culturais integrados neste sentido, então há possibilidade de uma psiquiatria de alguma forma universal, uma psiquiatria metacultural porque ela integrou a culturalidade constitutiva do sujeito humano para, justamente, ir além das culturas e das modulações que cada uma impõe ao comportamento objetivo.

Versão inicial recebida em fevereiro de 2001

Versão revisada recebida em agosto de 2001 